\title{
Studies on Polynuclear Complexes. II. On the Formation of Polynuclear Cobalt(III) Complexes in Aged Solutions of Aqua- hydroxo[tris(2-aminoethyl)amine]cobalt(III) Perchlorate
}

\author{
EVA PORZSOLT, ${ }^{*}$ TORSTEN BERG and JANNIK BJERRUM
}

Chemistry Department I, Inorganic Chemistry, H. C. Ørsted Institute, University of Copenhagen, Universitetsparken 5, DK-2100 Copenhagen Ø

Ageing reactions in solutions of aquahydroxo[tris(2-aminoethyl)amine]cobalt(III) perchlorate have been studied. In our initial experiments we employed a temperature of $80{ }^{\circ} \mathrm{C}$. However, the cobalt nitrogen bonds were not sufficiently robust at this temperature and a series of unidentified decomposition products were formed during the ageing procedures. Experiments were therefore made at room temperature, the most important observation then being the slow formation of an orange-red polymer in $0.01 \mathrm{M}$ solutions of the cobalt(III) monomers. A stationary state entailing transformation of up to $60 \%$ of the cobalt into the polymer is established after about one year, and analysis of the aged solutions showed that no polymers other than the orange-red complex are formed in the diaquaaquahydroxo buffer range. The isolated polymer is labile and is rapidly converted back into the monomers in acid solution. It has no acid-base properties in the $\mathrm{pH}$ range $4-9$ and its absorption maxima $\left(\lambda(\mathrm{nm}), \varepsilon\left(1 \mathrm{~mol}^{-1} \mathrm{~cm}^{-1}\right): 500,134 ; 355,113\right)$ are situated $\sim 5 \mathrm{~nm}$ lower than those of the diaqua(tren) complex. The polymer was not isolated in the solid state, but it could be estimated from the experiments that $\sim 1.6$ protons per cobalt monomer are set free when the polymer is formed from the diaqua tren complex and a plausible constitution consistent with this observation is discussed. Some $\mathrm{Co}-\mathrm{N}$ bound-rupture occurs in the more basic solutions, $\quad \operatorname{tris}\{[$ di- $\mu$-hydroxo(tren) $]$ cobalt(III) $\}$ cobalt(III) perchlorate being isolated as one of the products formed.

\footnotetext{
* On leave from Institute of Physical Chemistry, Kossuth Lajos University, 4010 Debrecen 10, Hungary.
}

During a study ${ }^{1,2}$ of the acid-base equilibria in the diaquabis(ethylenediamine)cobalt(III) system it was found that solutions of monomers in the buffer region showed spectral changes attended by a fall in $\mathrm{pH}$ in the course of a few weeks or months. It was first believed that this was due to the process:

$2 \mathrm{Coen}_{2}\left(\mathrm{H}_{2} \mathrm{O}\right)_{2}{ }^{3+} \rightleftharpoons \mathrm{en}_{2} \mathrm{CO}_{\mathrm{HO}}^{\mathrm{OH}} \mathrm{Co} \mathrm{en}_{2}{ }^{4+}+2 \mathrm{H}^{+}$

However, the absorption spectrum of solutions prepared from tetrakis(ethylenediamine)di- $\mu$-hydroxodicobalt(III) nitrate changed in the course of a few days until they became identical with that of solutions of the monomeric system at the $\mathrm{pH}$ in question. This clearly rules out the possibility of explaining the ageing process by eqn. (1).

The formation of chain or ring polymers of the type:

$-\mathrm{Coen} n_{2}-\mathrm{OH}-\mathrm{Coen}_{2}-\mathrm{OH}-\mathrm{Coen}_{2}-\mathrm{OH}-\mathrm{Co}$
$\mathrm{en}_{2}-\mathrm{OH}-$

was another possibility. However, just as in "diol" formation, this type of polymerization cannot explain the fact that solutions of the aquahydroxobis(ethylenediamine) salt with one $\mathrm{OH}$ per cobalt monomer produce hydrogen ions during the polymerization process.

The two chelated ethylenediamine molecules were at first thought not to be engaged in the ageing reactions. However, it was noted that the 
solutions changed more rapidly in glass than in paraffined vessels and that addition of charcoal had a striking effect. Charcoal evidently catalyzes dissociation of ethylenediamine with the results that the solutions instead of becoming more acidic became more basic. The experiments mentioned were all performed at room temperature, but some subsequent experiments performed by Sven Harnung of this department have shown that the use of higher temperatures also results in some decomposition of the complexes leading to an increase in $\mathrm{pH}$.

In the hope of avoiding such decomposition we have studied the ageing reactions occurring in the analogous cobalt(III) system with the tetradentate ligand tris(2-aminoethyl)amine (in the following abbreviated tren). This ligand has the advantage for our purposes that it occupies four facial positions for steric reasons, so that only two cis positions are left for the ageing reactions, assuming that the $\mathrm{Co}-\mathrm{N}$ bonds are sufficiently robust.

In order to obtain results in a reasonably short time, our first experiments with the cobalt(III) tren complexes were made at $80^{\circ} \mathrm{C}$. However, contrary to expectations some cobalt-nitrogen bond rupture took place at this temperature and separation of the reaction mixture on Sephadex columns showed that a complex mixture of unidentified products was formed. In the following section the experiments at

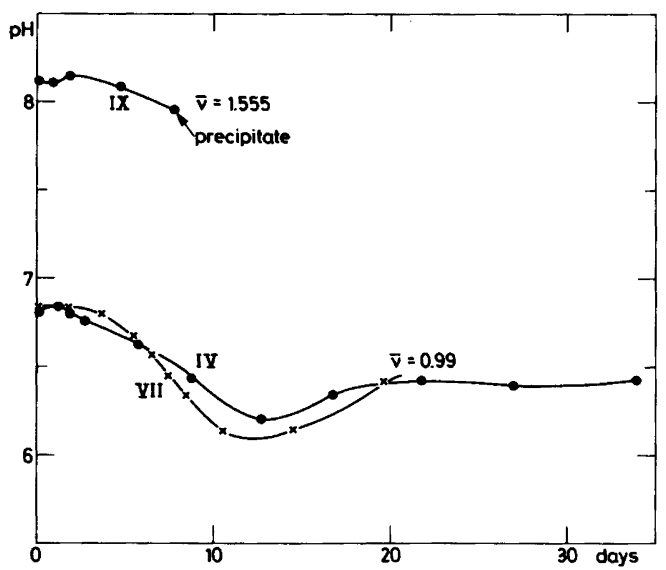

Fig. 1. The change in $\mathrm{pH}$ with time at $80{ }^{\circ} \mathrm{C}$ for solutions with various $\bar{v} . C_{\mathrm{NaClO}_{4}}=1.00 \mathrm{M}$ in the solutions and the cobalt concentrations $C_{\mathrm{Co}}$ were as follows: IV, 0.00997; VII, 0.01028 ; IX, $0.00965 \mathrm{M}$. The measurements were made at $25^{\circ} \mathrm{C}$ on samples taken at intervals.
$80{ }^{\circ} \mathrm{C}$ are dealt with. We then describe the more successful experiments at room temperature, in which cobalt-nitrogen bond rupture was unimportant in relation to the ageing reactions.

Ageing experiments with the cobalt(III)tren complexes in $1 \mathrm{M} \mathrm{NaClO}_{4}$ at $80{ }^{\circ} \mathrm{C}$. The solutions of the aqua-hydroxo complex were made up in $1 \mathrm{M}$ $\mathrm{NaClO}_{4}$ from the anhydrous perchlorate salt, $\left[\mathrm{Co} \operatorname{tren}(\mathrm{OH}) \mathrm{H}_{2} \mathrm{O}\right]\left(\mathrm{ClO}_{4}\right)_{2}$. Solutions of this salt with or without addition of $\mathrm{HClO}_{4}$ and (or) $\mathrm{NaOH}$ are characterized in the following by their cobalt concentration $C_{\mathrm{Co}}$ and by $\bar{v}$, the average number of protons released initially per cobalt atom:

$\bar{v}=\frac{C_{\mathrm{Co}}-C_{\mathrm{HNO}_{3}}+C_{\mathrm{NaOH}}+\left[\mathrm{H}^{+}\right]-\left[\mathrm{OH}^{-}\right]}{C_{\mathrm{Co}}}$

if $\left|C_{\mathrm{HNO}_{3}}-C_{\mathrm{NaOH}}\right| \lesssim C_{\mathrm{Co}}$.

The way in which the ageing reactions influence $\mathrm{pH}$ in $\sim 0.01 \mathrm{M}$ complex solutions with different $\bar{v}$ is shown in Fig. 1. The reactions are surface catalyzed and therefore not completely reproducible. However, Fig. 1 shows clearly that the initial

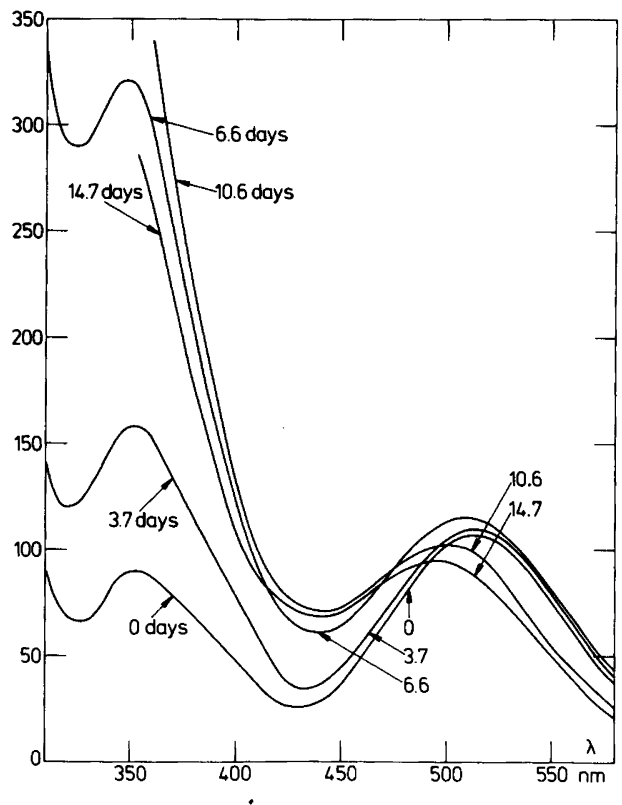

Fig. 2. Changes in the absorption spectrum of solution VII $\left(C_{C_{0}}=0.0128\right.$ and $\left.\bar{v}=0.99\right)$ during the ageing process at $80{ }^{\circ} \mathrm{C}$. Samples were taken at intervals and measurements made at $25{ }^{\circ} \mathrm{C}$. The figures on the curves indicate the number of days from the start of the experiment. 
reactions for solutions with $\bar{v}=0.99$ and 1.555 produce a decrease in $\mathrm{pH}$ which is followed after some days by reactions which increase $\mathrm{pH}$, and which for $\bar{v}=1.555$ lead to precipitation.

The effect of the ageing reactions on the absorption spectrum of solution VII with $\vec{v}=0.99$ is shown in Fig. 2. The band in the visible region shows, like the changes in $\mathrm{pH}$, two opposite effects: first a small intensity increase followed, after about one week, by a decrease, the absorption maximum in both cases shifting towards lower wavelength. On the other hand, the very large increase in the ultraviolet absorption intensity suggests extensive decomposition of the complexes.

In the case of solution VII the formation of a very complex mixture of compounds during the ageing reactions was shown directly by separation on Sephadex columns. Some analytical results from this experiment, in which the percentage of cobalt in each fraction was determined by atomic absorption spectrometry (see Experimental), are shown in Table 1. It can be seen that at least six coloured fractions are formed in the solution after keeping it at $80{ }^{\circ} \mathrm{C}$ for about 12 days.

Table 1. Separation of the components of solution VII $(\bar{v}=0.99)$ at various stages of the ageing process. $0.2-0.6 \mathrm{M} \mathrm{NaClO}_{4}$ solutions $(\mathrm{pH} \sim 3)$ were used as eluent.

\begin{tabular}{clc}
\hline Days & Colour of fractions & Co \% \\
\hline 3.7 & red & 93 \\
& orange-red & weak \\
& violet & $\sim 1$ \\
& & \\
6.6 & orange-red & 86 \\
& red & 2 \\
& reddish brown & Residue \\
& greyish & 31 \\
7.5 & orange-red & 67 \\
& red & 4 \\
& brown & Residue \\
& greyish & 38 \\
12.5 & violet & 20 \\
& orange-red & 2 \\
& reddish brown & 20 \\
& violet & 8 \\
& yellow & 11 \\
& brown & Residue \\
\hline
\end{tabular}

Their presence is indicative of the existence of a number of new polymeric cobalt(III) complexes, although identification of these will require further work. However, the red fraction dominating during the first week of the reaction can be ascribed to the equilibrium mixture of the monomeric cobalt(III) tren complexes. It should be noted that an orangered fraction appears to be the initial reaction product. This compound will be dealt with in more detail in the following section.

Results of the ageing experiments at room temperature. Portions of solutions Nos. $\mathrm{I}-\mathrm{X}$ which were to be used in the experiments at $80{ }^{\circ} \mathrm{C}$ were set aside and used to follow the slow ageing reactions at room temperature. Changes in $\mathrm{pH}$ and extinction coefficients for solutions Nos. I - VII (having $\bar{v} \sim 0.5$ and $\sim 1.0$ ) after about 500 days are described in Table 2. All of these solutions have become considerably more acidic during the 16 months in which they have been maintained at room temperature. It is also noteworthy that the five solutions having $\bar{v} \sim 1$ and $C_{\mathrm{Co}}$ varying from 0.005 to $0.02 \mathrm{M}$ have exhibited very similar $\mathrm{pH}-$ and extinction coefficient changes. It is known from the separation experiments on Sephadex columns that apart from the mononuclear complexes only one polymer is formed in the solutions having $\bar{v} \lessgtr 1$. This polymer is probably identical with the orange-red complex formed initially in the experiments at $80^{\circ} \mathrm{C}$, and it should be mentioned that after 500 days solution I was found to contain $\sim 21 \%$ of the cobalt in the form of this polymer, $\sim 75 \%$ in the mononuclear aquahydroxo system, and only about $3 \%$ as unidentified residue. By making certain assumptions it should therefore be possible to calculate the spectrum of the polymer from the data given in Table 2.

Calculation of the absorption spectrum of the orange-red polymer. In order to calculate the spectrum of the orange-red polymer it is necessary to know the number of protons per cobalt which are released during its formation. For this purpose we know that solutions VIII and IX in Table 5, both having $\bar{v} \sim 1.5$, become more acidic during the ageing process, whereas solution $\mathrm{X}$ having $\bar{v}=1.9$ becomes more basic. We have therefore tentatively assumed that 1.6 protons per cobalt are released during the formation of the polymer from the diaqua tren complex.

If we denote the formal cobalt concentration in the polymer by $x$ and the average number of protons released from the diaqua complex in the 
Table 2. Extinction coefficients for the diaqua-, dihydroxo- and aquahydroxotren cobalt(III) ions, and the changes in $\mathrm{pH}$ and extinction coefficients during ageing of solutions I-VII with $\bar{v} \leqq 1.00$. $\mathrm{C}_{\mathrm{NaClO}_{4}}=1.00 \mathrm{M}, 25^{\circ} \mathrm{C}$.

\begin{tabular}{|c|c|c|c|c|c|c|c|c|c|c|c|}
\hline Solution & $C_{\mathrm{Co}}$ & $\bar{v}$ & $\mathrm{pH}$ & days & 560 & 530 & 510 & 490 & 450 & 430 & $410 \mathrm{~nm}$ \\
\hline Diaqua & 0.00809 & 0 & $\sim 2$ & 0 & 47.0 & 90.0 & 107.1 & 101.6 & 41.8 & 19.8 & 17.9 \\
\hline Dihydroxo & 0.00798 & 2 & $\sim 11$ & 0 & 77.0 & 116.0 & 117.0 & 92.8 & 28.7 & 21.6 & 44.9 \\
\hline Aquahydroxo & - & 1 & - & 0 & 69.0 & 103.4 & 110.0 & 95.0 & 38,2 & 27.7 & 40.1 \\
\hline \multirow[t]{3}{*}{ I } & 0.01006 & 0.494 & 5.68 & 0 & 55.5 & 95.0 & 110.0 & 100.8 & 41.7 & 25.2 & 28.6 \\
\hline & 0.01006 & 0.494 & 5.68 & 21 & 55.8 & 95.0 & 109.4 & 99.4 & 40.7 & 24.4 & 28.8 \\
\hline & 0.01006 & 0.494 & 4.86 & 499 & 48.2 & 95.5 & 115.1 & 108.2 & 43.7 & 22.4 & 23.8 \\
\hline \multirow[t]{2}{*}{ II } & 0.00994 & 0.591 & 5.83 & 0 & 58.5 & 97.5 & 110.0 & 100.1 & 36.0 & 30.6 & 30.6 \\
\hline & 0.00994 & 0.591 & 4.93 & 499 & 49.3 & 98.8 & 118.5 & 111.9 & 44.3 & 22.2 & 24.6 \\
\hline \multirow{2}{*}{ III } & 0.00515 & 0.979 & 6.79 & 0 & 68.0 & 104.3 & 112.5 & 97.3 & 38.9 & 29.5 & 39.0 \\
\hline & 0.00515 & 0.979 & 5.12 & 500 & 48.5 & 104.9 & 130.0 & 123.1 & 48.5 & 25.2 & 29.1 \\
\hline \multirow[t]{2}{*}{ IV } & 0.00997 & 0.989 & 6.82 & 0 & 68.4 & 103.4 & 111.4 & 95.4 & 37.4 & 26.9 & 39.1 \\
\hline & 0.00997 & 0.989 & 5.12 & 500 & 49.1 & 103.1 & 125.2 & 116.2 & 44.1 & 24.1 & 30.1 \\
\hline \multirow[t]{2}{*}{ V } & 0.01992 & 0.997 & 6.85 & 0 & 67.3 & 103.4 & 112.4 & 95.2 & 36.9 & 26.9 & 38.7 \\
\hline & 0.01992 & 0.997 & 5.12 & 500 & 52.1 & $(106)$ & - & - & 48.2 & 26.2 & 32.6 \\
\hline \multirow[t]{2}{*}{ VI } & 0.01007 & 0.969 & 6.75 & 0 & 68.0 & 104.0 & 113.0 & 98.3 & 39.1 & 28.3 & 37.2 \\
\hline & 0.01007 & 0.969 & 5.19 & 499 & 51.7 & 106.2 & 131.0 & 122.0 & 46.9 & 26.0 & 31.5 \\
\hline \multirow[t]{3}{*}{ VII } & 0.01028 & 0.991 & 6.83 & 0 & 62.2 & 98.8 & 106.1 & - & 36.4 & 25.6 & 37.0 \\
\hline & 0.01028 & 0.991 & 6.70 & 20 & 68.5 & 104.8 & 113.0 & 97.8 & 40.4 & 30.3 & 43.5 \\
\hline & 0.01028 & 0.991 & 519 & 470 & 49.8 & 104.4 & 129.2 & 122.5 & 48.5 & 27.2 & 32.6 \\
\hline
\end{tabular}

equilibrium system of the monomers by $\bar{n}$, we obtain the following equation which is valid subject to the assumptions made:

$\bar{v} C_{\mathrm{Co}}=\bar{n}\left(C_{\mathrm{o}}-x\right)+1.6 x$

or

$x=\frac{C_{\mathrm{Co}}(\bar{v}-\bar{n})}{(1.6-\bar{n})}$

From this expression $x$ can be calculated. $C_{\mathrm{Co}}$ and $\bar{v}$ are known for the initial solutions, and $\bar{n}=\alpha_{1}+2 \alpha_{2}$ as well as the fractions of diaqua $\left(\alpha_{0}\right)$, aquahydroxo $\left(\alpha_{1}\right)$ and dihydroxo $\left(\alpha_{2}\right)$ ions can be calculated from the $\mathrm{pH}$ in the aged solutions and the dissociation constants of the diaqua ion: $\mathrm{p} K_{1}=5.69, \mathrm{p} K_{2}=8.04$ (see Experimental).

If we furthermore introduce the molar extinction coefficients of the diaqua $\left(\varepsilon_{0}\right)$, aquahydroxo $\left(\varepsilon_{1}\right)$ and dihydroxo $\left(\varepsilon_{2}\right)$ ions at a given wavelength, the extinction coefficient $\left(\varepsilon_{\mathrm{x}}\right)$ of the polymer at this wavelength can be calculated from eqn. (4).

$x \varepsilon_{\mathrm{x}}=C_{\mathrm{Co}} \varepsilon_{\mathrm{av}}-\left(C_{\mathrm{Co}}-x\right)\left(\alpha_{0} \varepsilon_{0}+\alpha_{1} \varepsilon_{1}+\alpha_{2} \varepsilon_{2}\right)$

where $\varepsilon_{\mathrm{av}}$ is the experimental extinction coefficient for the aged solutions. The values of $\varepsilon_{0}$ and $\varepsilon_{2}$ given in Table 2 were measured directly for acidic and basic solutions, and the value of $\varepsilon_{1}$ was calculated from the average spectrum of the solutions having $\bar{v} \sim 0.99$ and the following distribution of the complexes: $\alpha_{0}=0.064, \alpha_{1}=0.882, \alpha_{2}=0.054$.

Results of the calculations for solutions I-VII are shown in Table 3. The fraction $\alpha_{\mathrm{x}}=x / C_{\mathrm{Co}_{\mathrm{o}}}$ of the polymer varies from 0.25 for $\bar{v} \sim 0.5$ to as much as $\sim 0.6$ for $\bar{v}=1$. The value $\alpha_{\mathrm{x}}=0.25$ for solution $\mathrm{I}$ is seen to be in good agreement with the value of 0.21 obtained in the previously-mentioned direct determination employing Sephadex columns. It should also be noted that there is fair agreement between the values of the extinction coefficients for the polymer calculated for the various solutions. 
Table 3. Calculated extinction coefficients for the orange-red polymer in aged solutions of the cobalt(III) tren system.

\begin{tabular}{rlllllllllll}
\hline No. & $C_{\text {Co }}$ & $\bar{v}$ & $\bar{n}$ & $x$ & 560 & 530 & 510 & 490 & 450 & 430 & $410 \mathrm{~nm}$ \\
\hline I & 0.01006 & 0.494 & 0.129 & 0.00250 & 43 & 106 & 138 & 132 & 51 & 27 & 34 \\
II & 0.00994 & 0.591 & 0.147 & 0.00303 & 47 & 113 & 145 & 136 & 51 & 24.7 & 33 \\
III & 0.00515 & 0.979 & 0.214 & 0.00292 & 46 & 114 & 147 & 141 & 54.5 & 28.1 & 34 \\
IV & 0.00997 & 0.989 & 0.213 & 0.00565 & 46 & 109 & 136 & 127 & 46 & 25.6 & 35 \\
V & 0.01992 & 0.997 & 0.212 & 0.01130 & 52 & 122 & 142 & 140 & 53.5 & 29.2 & 41 \\
VI & 0.01007 & 0.969 & 0.242 & 0.00563 & 69 & 117 & 149 & 140 & 51.5 & 28.4 & 45 \\
VII & 0.01028 & 0.991 & 0.239 & 0.00575 & 46 & 113 & 146 & 140 & 55 & 31.5 & 40 \\
\hline
\end{tabular}

Table 4. Calculated extinction coefficients for the hypothetical polymer in aged solutions of the cobalt(III) bis(ethylenediamine) system (based on data given by Rasmussen and Bjerrum ${ }^{2}$ ). Extinction coefficients of the cis-trans equilibrium mixture of the monomers are also given.

\begin{tabular}{|c|c|c|c|c|c|c|c|c|c|c|c|}
\hline$C_{\mathrm{Co}}$ & $\bar{v}$ & $\mathrm{pH}$ & $\bar{n}$ & $x$ & 540 & 520 & 500 & 440 & 420 & 410 & $380 \mathrm{~nm}$ \\
\hline 0.01013 & 0.50 & 5.047 & 0.147 & 0.00246 & 93 & 126 & 124 & 24 & 21 & 31 & 134 \\
\hline 0.00989 & 0.49 & 5.837 & 0.166 & 0.00223 & 106.5 & 143 & 140 & 24.6 & 22 & 34 & 104 \\
\hline 0.00855 & 1.00 & 5.577 & 0.371 & 0.00438 & 93 & 125 & 124 & 26.7 & 24.4 & 26.2 & 101 \\
\hline \multirow{3}{*}{0.00974} & 1.00 & 5.747 & 0.468 & 0.00457 & 92 & 124 & 123 & 24.7 & 22.5 & 32 & 96.6 \\
\hline & & & & Average & 96 & 129 & 128 & 25 & 22.4 & 30.8 & 109 \\
\hline & & & & Diaqua & 41.6 & 62.6 & 79.4 & 29.6 & 14.9 & 14.2 & 44.0 \\
\hline \multirow[t]{2}{*}{ i } & & & & Dihydroxo & 63.6 & 71.0 & 65.6 & 20.6 & 24.2 & 37.0 & 73.6 \\
\hline & & & & Aquahydroxo & 61.5 & 71.2 & 71.1 & 32.9 & 37.4 & 46.2 & 73.6 \\
\hline
\end{tabular}

An analogous calculation of the extinction coefficients of a corresponding hypothetical polymer in aged solutions of the cobalt(III) bis(ethylenediamine) system was made using the data given by Rasmussen and Bjerrum. ${ }^{2}$ The results of such a calculation for solutions showing a sufficient change in $\mathrm{pH}$ during ageing for more than 400 days (solutions 2, 3,5 and 6) are shown in Table 4. The values for the extinction coefficients of the equilibrated cis/trans diaqua, dihydroxo and aquahydroxo monomers used in the calculation are also also given. Eqns. (3) and (4) were used, and the calculations of $\alpha_{0}, \alpha_{1}, \alpha_{2}$ and $\bar{n}$ were made using the following dissociation constants for the cis/trans equilibrated diaqua ions: $\mathrm{p} K_{1}=5.81, \mathrm{p} K_{2}=8.10$ $\left(1 \mathrm{M} \mathrm{KNO}_{3}, 25^{\circ} \mathrm{C}\right) .{ }^{1}$

The absorption spectrum and extinction coefficients estimated for the orange-red polymeric tren and ethylenediamine species are compared in Fig. 3 with the spectra of the corresponding diaqua and dihydroxo monomers.

Direct measurements of the spectrum of the orangered tren cobalt(III) polymer. Data for the solutions used for these measurements are given in Table 5 . The aged solutions are probably all very close to being at equilibrium. For example, it was observed that the spectrum of VIII did not change significantly after about 400 days. During the first year of ageing solutions VIII and IX, both having $\bar{v} \sim 1.5$, deposited a few milligrams of irregular, almost black crystals. These crystals were identified by analysis and by their solution spectrum $\left(\lambda_{\max } 622,495\right.$ and $310 \mathrm{~nm})$ as tris $\{[\mathrm{di}-\mu$-hydroxo(tren) $)] \operatorname{cobalt}(\mathrm{III})\}-$ cobalt(III) perchlorate, analogous to the so-called "Werner's brown salts", ${ }^{3}$ (see Experimental).

The aged solutions referred to in Table 5 were analyzed on Sephadex columns and the results are summarized in Table 6 . The first fractions contained the orange-red polymer and the second fractions the equilibrium mixture of the monomers. It will also be noted that the orange-red polymer is so labile that a change in the $\mathrm{pH}$ of the eluent from $\sim 5$ to $\sim 2$ (in the case of solution IX) reduces the percentage of isolated polymer from 66 to $10 \%$ and increases the percentage of the aquahydroxo mixture from 6 to $72 \%$. The violet labile third frac- 


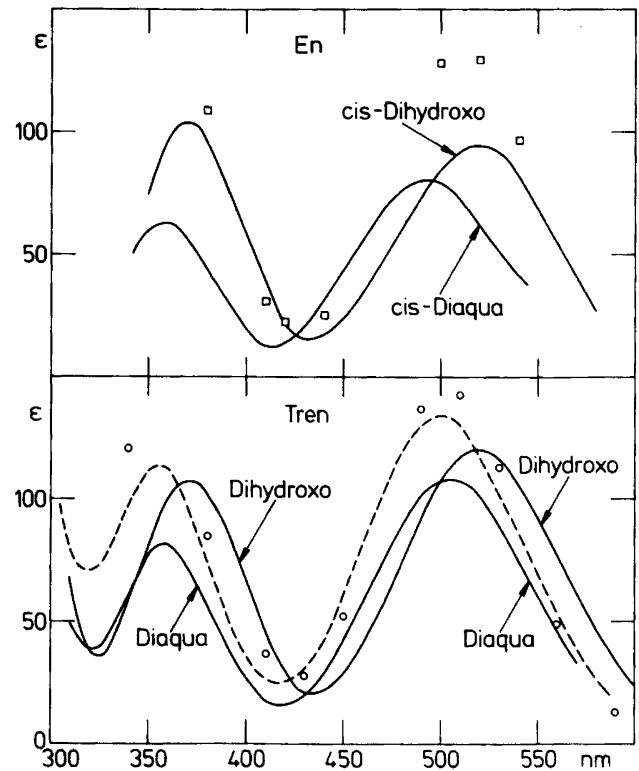

Fig. 3. The lower part of the figure shows the directlymeasured spectrum of the orange-red polymer (-- ) and of the diaqua- and dihydroxo(tren)cobalt(III) complexes. The O-points show the extinction coefficients (from Table 3 ) for the polymer calculated on the basis of data for the aged solutions.

The upper part of the figure shows the spectra of the cis-diaqua- and cis-dihydroxobis(ethylenediamine)cobalt(III) complexes, and the $\square$-points show the calculated values (from Table 4) for the hypothetical polymer formed in aged bis(ethylenediamine)cobalt(III) solutions.

Table 5. Data for solutions of the aquahydroxo(tren)cobalt(III) salt in $1 \mathrm{M} \mathrm{NaClO}_{4}(\bar{v}>1)$ aged at room temperature.

\begin{tabular}{cllcc}
\hline No. & $C_{\mathrm{Co}}$ & $\bar{v}$ & $\mathrm{pH}$ & $\begin{array}{l}\text { Time of } \\
\text { ageing (days) }\end{array}$ \\
\hline VIII & 0.00942 & 1.437 & 7.43 & 0 \\
& 0.00866 & - & 6.42 & 866 \\
IX & 0.00965 & 1.555 & 8.14 & 0 \\
& 0.00936 & - & 6.70 & 816 \\
X & 0.00788 & 1.90 & 9.02 & 0 \\
& 0.00788 & - & 9.53 & 383 \\
\hline
\end{tabular}

Table 6. Sephadex column separations of the components of the aged solutions referred to in Table 5. $0.15-0.7 \mathrm{M} \mathrm{NaClO}_{4}$ solutions were used as eluents for VIII and IX, and $0.2-0.5 \mathrm{M} \mathrm{NH}_{4} \mathrm{Cl}, \mathrm{NH}_{3}$ buffer solutions for $\mathrm{X}$. Figures give the percentage of total cobalt present.

\begin{tabular}{lcccc}
\hline & VIII & \multicolumn{1}{c}{ IX } & IX & \multicolumn{1}{c}{ X } \\
pH in eluent & $\sim 5$ & $\sim 5$ & $\sim 2$ & $\sim 9$ \\
\hline 1. Fraction, \% Co & 52 & 66 & 10 & 62 \\
2. Fraction, \% Co & 44 & 6 & 72 & 11 \\
3. Fraction, \% Co & - & 16 & 4 & 4 \\
Left on column, \% Co & 5 & 12 & 14 & 23 \\
\hline
\end{tabular}

tion obtained from solution IX could not be identified. The brownish-yellow third fraction obtained from solution $\mathrm{X}$ was found to contain tris $\{[$ di- $\mu$-hydroxo(tren) $]$ cobalt(III) $\}$ cobalt(III) complex. The amount of higher polymers and decomposition products left on the columns, which was negligible in the case of the more acidic solutions for $\bar{v} \leqslant 1$, is seen to increase with increasing basicity of the solutions.

The absorbance and the cobalt concentration of isolated fractions of the orange-red polymer were measured in several cases, and the extinction coefficients obtained are summarized in Table 7 . It is especially noteworthy how well the extinction coefficients estimated indirectly from measurements on solutions I-VII (Table 3) agree with the directly measured extinction coefficients obtained for the isolated polymer fractions from solutions VIII $-\mathrm{X}$. The best spectrum, especially in the ultraviolet part of the spectrum, was observed for a polymer fraction from solution $\mathrm{X}$ in which the cobalt concentration had been increased about 10 fold by repeated elution. ${ }^{4}$ The lack of acid-base properties, and the essential constancy of the absorption spectrum (within $\leq 1 \%$ ) of the orange-red polymer in the pH-range 4 to 9 was also established using this fraction. Unfortunately the cobalt concentration in this fraction was poorly determined and the extinction coefficients have therefore been fitted to the other data by assuming $\varepsilon_{510}=130 \mathrm{I} \mathrm{mol}^{-1} \mathrm{~cm}^{-1}$.

The orange-red polymer is very labile at low $\mathrm{pH}$ as can be seen from the data shown in Table 6 and decomposes in acidic solution to give the diaqua(tren) complex.

The solutions employed in the experiments discussed until now all had $C_{\text {Co }} \sim 0.01 \mathrm{M}$. More pronounced polymer formation would be expected 
Table 7. Comparison of calculated and directly measured molar extinction coefficients for the orange-red cobalt(III) tren polymer. $C_{\mathrm{Co}}$ in the isolated fractions varied from 0.3 to $0.7 \mathrm{mM}$ in VIII and IX, to $\sim 5 \mathrm{mM}$ in $\mathrm{X}$.

\begin{tabular}{lllllllll}
\hline No. & Method & 560 & 530 & 510 & 490 & 450 & 430 & $410 \mathrm{~nm}$ \\
\hline VIII & Direct & 52 & 100 & 125 & 122 & 62.5 & 46 & 54 \\
IX & Direct & 44 & 103 & 134 & 128 & 52 & 30 & 38 \\
X & Direct & 54 & 104 & $(130)$ & 130 & 61 & 32 & 27 \\
I-VII & Calc. & 49 & 113 & 143 & 137 & 52 & 28 & 37 \\
\hline
\end{tabular}

in solutions with a higher cobalt concentration and to examine this a solution having $C_{\mathrm{Co}}=0.067 \mathrm{M}$ and $\bar{v}=1.5$ was studied. The results of the analysis of this solution after ageing for 380 days are shown in Table 8. It can be seen that as many as 7 fractions are obtained in this case. The first fraction contains the orange-red polymer and the second fraction the equilibrium mixture of the monomers. Of the other fractions only the 7 th, showing maxima at 620,426 and $308 \mathrm{~nm}$, could be identified as containing the tris $\{[$ di- $\mu$-hydroxo(tren) $]$ cobalt(III) $\}$ cobalt(III) complex. Considerably more work will be necessary to identify (and if possible obtain solid salts of) the complexes present in the remaining fractions. In this connection it can be mentioned that an attempt to isolate the iodide salt of the labile orange-red polymer led to the precipitation after some hours of a small quantity of crystalline material which was analyzed for aquahydroxo(tren)cobalt(III) iodide.

\section{DISCUSSION}

The main result of the work described here is the observation of the slow formation of an orange-red polymeric complex in dilute $(\sim 0.01 \mathrm{M})$ solutions of the aquahydroxo(tren)cobalt(III) system. A stationary state involving up to $60 \%$ of the cobalt in the form of the polymer is attained after about one year at room temperature. Furthermore, analysis of aged solutions of the monomeric system having a neutralization degree $\bar{v} \leq 1$ has shown that no polymers other than the orange-red species are formed at room temperature. Solutions with $\bar{v} \simeq 1.5$ become more acidic, and solutions with $\bar{v}=1.9$ more basic during the ageing process (see Table 5). Some formation of other complexes occurs in aged solutions with $\bar{v} \geq 1.5$, but there is nothing to indicate that tren functions as a tridentate ligand by the formation of the orange-red polymer. The cobalt(III) ions must therefore have only two coordination sites remaining for bridged complex formation and this restriction reduces the number

Table 8. Analysis of a more concentrated cobalt(III) tren solution $\left(C_{\mathrm{C}_{0}}=0.067 \mathrm{M}, \bar{v}=1.5\right)$ aged at room temperature for about 380 days. $\mathrm{NaCl}$ solution was used as eluent.

\begin{tabular}{lllllll}
\hline $\begin{array}{l}\text { No. of } \\
\text { fraction }\end{array}$ & Co $\%$ & $\begin{array}{l}\text { Colour of } \\
\text { fraction }\end{array}$ & $\mathrm{pH}$ & \multicolumn{2}{l}{$\begin{array}{l}\text { Band maxima } \\
(\lambda \text { in } \mathrm{nm})\end{array}$} & $\varepsilon(\sim 500) / \varepsilon(\sim 360)$ \\
\hline 1 & $\sim 35$ & orange-red & $4-9$ & $500, \quad 354$ & $\sim 1.25$ \\
2 & $\sim 5$ & as monomers & 4 & $500, \quad 358$ & $\sim 1.32$ \\
3 & & & 4 & $508, \quad 358$ & $\sim 1.25$ \\
4 & $\sim 30$ & red & 9 & $508, \quad 361$ & $\sim 1.3$ \\
5 & $\sim 25$ & violet & $4-9$ & $523, \quad 362$ & $\sim 0.85$ \\
6 & $\sim 1.3$ & red & $4-9$ & $510, \sim 365$ & $\sim 1.25$ \\
7 & $\sim 1.2$ & blue & $4-9$ & $528, \quad 368$ & $\sim 1.0$ \\
Residue & $\sim 0.5$ & brownish & $4-9$ & $620, \quad 496, \quad 308$ & \\
\hline
\end{tabular}

Acta Chem. Scand. A 32 (1978) No. 4 
Table 9. Absorption maxima for some cobalt(III) tren complexes.

\begin{tabular}{|c|c|c|c|c|c|c|c|}
\hline Complex & $\lambda_{\max , 1}$ & $\varepsilon$ & $\lambda_{\max , 2}$ & $\varepsilon$ & $\lambda_{\max , 3}$ & $\varepsilon$ & Reference \\
\hline Orange polymer & 500 & 134 & 355 & 113 & & & This paper \\
\hline \multirow{2}{*}{ Co tren $\left(\mathrm{H}_{2} \mathrm{O}\right)_{2}{ }^{3+}$} & 505 & 107.5 & 360 & 81 & & & This paper \\
\hline & 504 & 109 & 360 & 81 & & & Scheidegger ${ }^{5}$ \\
\hline \multirow{2}{*}{ Co tren $(\mathrm{OH}) \mathrm{H}_{2} \mathrm{O}^{2+}$} & 512 & 110 & 355 & 82 & & & This paper \\
\hline & 513 & 100 & 355 & 65 & & & Bösch ${ }^{6}$ \\
\hline \multirow{2}{*}{ Co tren $(\mathrm{OH})_{2}{ }^{+}$} & 520 & 120 & 370 & 107 & & & This paper \\
\hline & 520 & 119 & 370 & 117 & & & Scheidegger ${ }^{5}$ \\
\hline \multirow{3}{*}{$\begin{array}{l}\left\{\operatorname{tren} \mathrm{Co}(\mathrm{OH})_{2} \mathrm{Co} \text { tren }\right. \\
\mathrm{Co}\left\{(\mathrm{OH})_{2} \mathrm{Co} \text { tren }\right\}_{3}{ }^{6+}\end{array}$} & 526 & 129 & 368 & 170 & 300 & 3890 & Bösch ${ }^{60}$ \\
\hline & 622 & 117 & 495 & 372 & 310 & 6020 & This paper \\
\hline & 623 & 135 & 500 & 468 & 311 & 7410 & Bösch ${ }^{6}$ \\
\hline
\end{tabular}

of possibilities for the constitution of the complex. The proposal expressed by eqn. (5) corresponding

Co tren $(\mathrm{OH}) \mathrm{H}_{2} \mathrm{O}^{2+}+2 \mathrm{Co} \operatorname{tren}(\mathrm{OH})_{2}{ }^{+} \rightarrow$ $\mathrm{O}(\mathrm{Co} \text { tren } \mathrm{OH})_{3}{ }^{4+}+2 \mathrm{H}_{2} \mathrm{O}$

to $\bar{v}=1.67$ is consistent with the data. In Fig. 3 (lower part) the absorption spectrum of the polymer is compared with those of the diaqua and dihydroxo(tren)cobalt(III) complexes. The data for the absorption maxima are given in Table 9 and it will be noted that the absorption maxima for the polymer are situated $\sim 5 \mathrm{~nm}$ lower than those for the diaqua tren complex. This is consistent with the orange colour of the polymer and supports our assumption that the four $\mathrm{Co}-\mathrm{N}$ bonds remain intact during the formation of the polymer. However, the relatively low absorption intensity in the ultraviolet may not support our assumption (cf. Table 9). Furthermore, although the ease with which the polymer is eluted from Sephadex columns is consistent with a relatively low charge per cobalt atom, we have still to explain the fact that the three $\mathrm{OH}$-groups in the proposed polymer do not show acid-base properties in the $\mathrm{pH}$-range 4-9. As regards the latter problem, it is possible that the compound has a structure in which the three $\mathrm{OH}$-groups are strongly hydrogen bonded to each other. To bring them within bonding distances the angle $\mathrm{Co}-\mathrm{O}-\mathrm{Co}$ has to be $120-125^{\circ}$, compared to $115^{\circ}$ in $\mathrm{H}_{3} \mathrm{O}^{+}$. In the basic chromium(III) acetate, $\mathrm{O}\left(\mathrm{Cr}\left\{\mathrm{O}_{>}>\mathrm{CCH}_{3}\right\}_{2} \mathrm{H}_{2} \mathrm{O}\right)_{3}{ }^{+}$, the three chromium atoms and the central oxygen lie in the same plane, ${ }^{7}$ but this is not a prerequisite in the case of diamagnetic cobalt(III) structures with no possibility of stabilization via $\pi$-bonding. A model of $\mathrm{O}(\mathrm{Co} \text { tren } \mathrm{OH})_{3}{ }^{4+}$ with a distance from cobalt to the central oxygen atom of $2.0 \AA$ shows, however, that the structure is so compact that only with difficulty is it possible to place the coordinated $\mathrm{NH}_{2}$ groups sufficiently far apart, e.g. $2.7 \AA$, from each other. On the other hand, the assumptions made are consistent with the fact that the polymer slowly undergoes changes when isolated from the solution in which it is formed and rapidly hydrolyzes to give the monomers in acidic solution.

The spectra of the diaqua- and dihydroxobis(ethylenediamine)cobalt(III) complexes and the $\lambda, \varepsilon$ values calculated for the hypothetical polymer in this system from the data of Rasmussen and Bjerrum $^{2}$ (see Table 4) are shown in the upper part of Fig. 3. The data provide some support for the proposal that this polymer has a constitution similar to that of the orange-red polymer in the tren system, but this remains to be confirmed by direct isolation of the polymer.

\section{EXPERIMENTAL}

Preparation of complexes. Aquahydroxo(tren)cobalt(III) perchlorate was prepared from the corresponding carbonato complex:

$\left[\mathrm{Co}\right.$ tren $\left.\left(\mathrm{CO}_{3}\right)\right] \mathrm{ClO}_{4} \cdot a q$ has been prepared previously by Scheidegger. ${ }^{5}$ Our procedure was as follows: A solution of $\mathrm{CoCl}_{2} \cdot 6 \mathrm{H}_{2} \mathrm{O}(23.8 \mathrm{~g}, 0.1 \mathrm{~mol})$ in a mixture of $30 \% \mathrm{H}_{2} \mathrm{O}_{2}(50 \mathrm{ml})$ and water $(250$ $\mathrm{ml}$ ) was slowly added to solid $\mathrm{KHCO}_{3}(100 \mathrm{~g})$. The green mixture was heated and vigorously stirred. After $10 \mathrm{~min}$ solid tren. $3 \mathrm{HCl}(25.4 \mathrm{~g}, 0.1 \mathrm{~mol})$ was added in small portions. The solution became reddish-brown and after heating for $10 \mathrm{~min}$ all the solid had dissolved. The solution was then evaporated to about one half of its original volume and after cooling to room temperature three volumes of methanol were added. About $90 \%$ of the $\mathrm{KCl}$ 
was precipitated in this way and after filtration the methanol was removed from the solution by evaporation and the remaining chloride by adding $0.2 \mathrm{M}$ $\mathrm{AgClO}_{4}$ dropwise until precipitation ceased. The mixture was filtered and after adding $3.5 \mathrm{M} \mathrm{LiClO}_{4}$ $(100 \mathrm{ml})$ the solution was cooled in ice and the carbonato perchlorate precipitated by adding ethanol $(500 \mathrm{ml})$. The dark red crystals of $\left[\mathrm{Co} \operatorname{tren}\left(\mathrm{CO}_{3}\right)\right] \mathrm{ClO}_{4} \cdot 2 \mathrm{H}_{2} \mathrm{O}$ were washed with ethanol and dried in air. The crude product was purified as follows: $50 \mathrm{~g}$ of the salt was stirred mechanically with $150 \mathrm{ml}$ of $99 \%$ ethanol for $1 \mathrm{~h}$ in order to remove the remaining $\mathrm{LiClO}_{4}$. After filtration the procedure was repeated twice.

$\left[\mathrm{Co} \operatorname{tren}(\mathrm{OH}) \mathrm{H}_{2} \mathrm{O}\right]\left(\mathrm{ClO}_{4}\right)_{2}$. [Co tren $\left.\left(\mathrm{CO}_{3}\right)\right]-$ $\mathrm{ClO}_{4} \cdot 2 \mathrm{H}_{2} \mathrm{O}(40 \mathrm{~g}, 0.1 \mathrm{~mol})$ was dissolved in the minimum volume of water at $80{ }^{\circ} \mathrm{C}$ and $5 \mathrm{M} \mathrm{HClO}_{4}$ was then added dropwise until $\mathrm{CO}_{2}$ evolution ceased. The solution was maintained at $80^{\circ} \mathrm{C}$ for a further $30 \mathrm{~min}$ and allowed to cool. After addition of saturated $\mathrm{NaClO}_{4}(20 \mathrm{ml})$ the ice-cold solution was slowly neutralized by addition of $2 \mathrm{M} \mathrm{NaOH}$. At pH 5-6 $\left[\mathrm{Co} \operatorname{tren}(\mathrm{OH}) \mathrm{H}_{2} \mathrm{O}\right]\left(\mathrm{ClO}_{4}\right)_{2}$ began to precipitate as red-violet crystals. Continuing with the neutralization $95-98 \%$ of the salt could be precipitated. The crystals were washed with ethanol and recrystallized from water. Anal. Calc. for Co tren $(\mathrm{OH}) \mathrm{H}_{2} \mathrm{O}\left(\mathrm{ClO}_{4}\right)_{2}$ : Co 13.42; C 16.14; $\mathrm{H}$ 4.82; $\mathrm{N} \mathrm{12.76;} \mathrm{Cl} 16.15$. Found: Co 13.39; C 16.26; H 4.79; N 12.81; Cl 15.94 .

$\mathrm{Co}\left\{(\mathrm{OH})_{2} \text { Co tren }\right\}_{3}\left(\mathrm{ClO}_{4}\right)_{6}$, which separated from some of the aged solutions of the cobalt(III) tren monomers, has recently been characterized by Bösch $^{6}$ (see Table 9). The following preparative route has been devised by us: $\mathrm{Co}\left(\mathrm{ClO}_{4}\right)_{2} \cdot 6 \mathrm{H}_{2} \mathrm{O}$ $(18.0 \mathrm{~g}, 0.05 \mathrm{~mol})$ was dissolved in water $(25 \mathrm{ml})$ and tren $(5.6 \mathrm{~g}, 0.0375 \mathrm{~mol})$ was added and the dark red mixture was filtered to remove a slight precipitate of cobalt oxide. The solution was stirred vigorously and aerated for $2 \mathrm{~h}$ and was then placed in a refrigerator at $5{ }^{\circ} \mathrm{C}$. After 5 days the precipitate of crude $\mathrm{Co}\left\{(\mathrm{OH})_{2} \mathrm{Co} \text { tren }\right\}_{3}\left(\mathrm{ClO}_{4}\right)_{6}$.aq $(9.8 \mathrm{~g})$ was isolated by filtration. The salt was recrystallized from water at $60{ }^{\circ} \mathrm{C}$.

The dark brown irregular crystals were subjected to an X-ray analysis by Mrs. Eva Bang. They crystallize in the monolinic system with the unit cell dimensions $a=23.67 \AA, b=13.47 \AA, c=32.96 \AA$ and $\beta=98.22^{\circ}$. Weissenberg photographs show an ordered-disordered structure and oscillation diagrams around the $b$-axis clearly show equatorial symmetry.

Solutions. The solutions of cobalt(III) tren complexes in $1 \mathrm{M} \mathrm{NaClO}_{4}$ were prepared by weighing the complex salt and pipetting or titrating from stock solutions of $\mathrm{NaClO}_{4}(5 \mathrm{M}), \mathrm{HClO}_{4}$ and $\mathrm{NaOH}$.
pH-Measurements. Hydrogen ion concentrations were measured relative to $10^{-3}-10^{-2} \mathrm{M}$ solutions of $\mathrm{HClO}_{4}$ in $1 \mathrm{M} \mathrm{NaClO}_{4}$, using a Radiometer PHM 52 digital pH-meter. A selected Radiometer glass electrode (type $6202 \mathrm{~B}$ ) with the theoretical $\mathrm{pH}$-dependence was used, and a $1 \mathrm{M} \mathrm{NaCl} / \mathrm{calomel}$ electrode was employed as reference.

The acid dissociation constants of the diaqua(tren)cobalt(III) complex were determined according to the method of Bjerrum and Rasmussen ${ }^{1}$ from measurements of the hydrogen ion concentration in a number of solutions having $\bar{v} \sim 0.5$ and $\bar{v} \sim 1.5$. The following values were obtained: $\mathrm{p} K_{1}=5.69$, $\mathrm{p} K_{2}=8.04\left(1 \mathrm{M} \mathrm{NaClO}_{4}, 25^{\circ} \mathrm{C}\right)$.

Spectrophotometric measurements. The absorption spectra were measured on a Cary 14 spectrophotometer with a thermostatted $\left(25^{\circ} \mathrm{C}\right)$ cell compartment. In a few cases a Cary 118 spectrophotometer was also used. Cells of pathlength 0.1 to $5 \mathrm{~cm}$ were used, the reference cells being filled with $1 \mathrm{M} \mathrm{NaClO}_{4}$ solution.

Analysis. The Co(III) species in the aged solutions were separated by cation-exchange chromatography on columns of Sephadex SP C-25. When necessary the eluates were concentrated employing the technique used by Andersen et al. ${ }^{4}$ The cobalt content in the various fractions was determined by atomic absorption spectrometry using a Perkin-Elmer, model 403, instrument.

Acknowledgements. This investigation was supported by a maintenance grant from "Statens Naturvidenskabelige Forskningsråd" to Dr. Eva Porzsolt which is gratefully acknowledged. Mrs. Eva Bang took part in some of the work. Our thanks are also due to Claus Schäffer for helpful discussions and to Dr. Martin Hancock for revising the English manuscript.

1. Bjerrum, J. and Rasmussen, S. E. Acta Chem. Scand. 6 (1952) 1265.

2. Rasmussen, S. E. and Bjerrum, J. Acta Chem. Scand. 9 (1955) 735.

3. Werner, A. Ber. Dtsch. Chem. Ges. 47 (1914) 1977.

4. Andersen, P., Berg, T. and Jacobsen, J. Acta Chem. Scand. A 29 (1975) 381.

5. Scheidegger, H. A. Diss., No. 3878, Eidgenöss. Techn. Hochschule, Zürich 1966.

6. Bösch, J. Diss., No. 4579, Eidgenöss. Techn. Hochschule, Zürich 1971.

7. Chang, S. C. and Jeffrey, G. A. Acta Crystallogr. B 26 (1970) 673.

Received November 4, 1977. 